\title{
Pengembangan e-modul menggunakan aplikasi flip pdf professional pada mata kuliah analisis kurikulum pendidikan dasar
}

\author{
Alzet $\operatorname{Rama}^{\left.{ }^{*}\right)}$, Rusnardi Rahmat Putra ${ }^{1}$, Yasdinul Huda $^{1}$, Remon Lapisa $^{1}$ \\ ${ }^{1}$ Fakultas Teknik Universitas Negeri Padang, Indonesia
}

\section{Article Info \\ Article history: \\ Received Des $12^{\text {th }}, 2021$ \\ Revised Jan $12^{\text {th }}, 2022$ \\ Accepted Jan $26^{\text {th }}, 2022$}

\section{Keyword:}

Modul

Android

Flip PDF Professional

Validitas

Praktikalitas

Efektifitas

\begin{abstract}
Penelitian ini bertujuan mengkaji tentang pengembangan modul analisis kurikulum pendidikan teknologi meliputi uji validitas, uji praktikalitas dan uji efektifitas. Penelitian ini termasuk dalam penelitian Research and Development $(R \& D)$. Model yang dipakai dalam penelitian ini menggunakan prinsip ADDIE, metode pengumpulan data melalui angket dan tes hasil belajar, analisis data diolah menggunakan pendekatan kuantitatif dari penerapan modul dan dideskripksikan melalui pendekatan kualititatif untuk meyimpulkan hasil penelitian, subjek penelitian terdiri dari dosen dan mahasiswa. Hasil penelitian yang dilakukan terhadap pengembangan modul berbasis android memenuhi kelayakan, ditinjau dari aspek validitas, praktikalitas dan efektifitas. Hasil analisis aspek validitas pengembangan modul dari validator ahli materi adalah $92,98 \%$ dengan kriteria sangat valid, sedangkan dari validator ahli media adalah 78,57\%, aspek praktikalitas pengembangan modul dari respon dosen pengampu skor persentase rata-rata $98,95 \%$ dan respon mahasiswa skor persentase rata-rata $87,76 \%$ dengan kriteria sangat praktis. Aspek efektifitas pengembangan modul dilihat dari tes kognitif hasil pembelajaran mahasiswa berupa pre-test dan post-test dengan menggunakan rumus gain score. Hasil tes pengetahuan pada 24 mahasiswa dan mendapatkan nilai skor rata-rata yang baik sebesar $74,29 \%$, sehingga mencapai kriteria sangat tinggi. Kesimpulan bahwa pengembangan modul pembelajaran berbasis android ini mampu menarik perhatian mahasiswa dan membuat mahasiswa paham terhadap materi serta membuat mahasiswa mampu bekerjasama dalam berkelompok.
\end{abstract}

(C) 2022 The Authors. Published by IICET.

This is an open access article under the CC BY-NC-SA license (https://creativecommons.org/licenses/by-nc-sa/4.0

\section{Corresponding Author:}

Rama, A.,

Fakultas Teknik Universitas Negeri Padang, Indonesia

Email: alzetrama8@gmail.com

\section{Pendahuluan}

Peningkatkan kemampuan dan aspek pembelajaran aspek kognitif afekif dan pisikomotor mahasiswa dosen menggunakan perangkat pembelajaran. Didalam perangkat pembelajaran terdapat berbagai unsur yang terdiri dari pendekatan, model, metode, strategi, taktik, media dan sumber belajar lainnya. Saat ini dosen menggunakan media yang digunakan dosen seperti buku cetak, modul cetak lembar kerja mahasiswa serta sumber buku cetak lainnya. Media pembelajaran yang digunakan juga media powerpoint yang membuat mahasiswa kurang tertarik disebabkan dosen yang menjelaskan dari powerpoint. 
Selain hal itu di tingkat pendidikan tinggi peserta didik sudah memasuki usia remaja menuju dewasa dengan menggunakan modul cetak membuat peserta didik akan bosan, karena hal yang terlihat oleh peserta didik merupakan lembar kertas dan tulisan beserta ilustrasi.

Mata kuliah analisis kurikulum pendidikan dasar yaitu matakuliah wajib yang diambil oleh mahasiswa jurusan Kurikulum Teknologi Pendidkan Fakultas Ilmu Pendidikan Universitas Negeri Padang. Mata kuliah analisis kurikulum pendidikan dasar mempunyai 3 SKS yang berada pada semester ganjil. Mata kuliah analisis kurikulum ini mempunyai bahan kajian tentang menganalisis kurikulum pada tingkat pendidikan dasar.

Berdasarkan hasil observasi dan wawancara dengan pengampu pada mata kuliah analisis kurikulum pendidikan dasar jurusan kurikulum teknologi pendidikan Universitas Negeri Padang di lapangan ditemukan pengampu memberikan materi dan tugas pembelajaran menggunakan media power point melalui metode ceramah. Pembelajaran dilaksanakan menggunakan media zoom dan menampilkan materi menggunakan powerpoint. Pengampu mata kuliah menyampaikan materi dengan metode ceramah dan diakhir pembelajaran memberikan tugas. Hal ini membuat Kurang semangatnya dan motivasi mahasiswa dalam memahami materi dan mengerjakan tugas. Mahasiswa yang ditugaskan pengampu mata kuliah untuk membaca modul cetak. Pengampu juga menyampaikan bahwa membutuhkan sebuah media yang terdapat video, materi dan kuis dalam media.

Proses pembelajaran yang dilakukan pengampu dengan menggunakan zoom dan metode ceramah banyak mahasiswa yang terkadang merasa bosan dan jenuh dalam pembelajaran. Permasalahan lainnya saat pelaksanaan pembelajaran mahasiswa banyak yang mematikan kamera zoom disebabkan pembelajaran yang membosankan dan tidak menarik bagi mereka, sehingga hasil belajar mahasiswa banyak yang kurang tercapainya tujuan dari materi yang diberikan.

\section{Kajian Teori}

Menurut (Sugiyono, 2013), metode research dan development (R\&D) yaitu sebuah metode yang dipakai dengan tujuan menciptakan produk dan mengevaluasi keefektifitasnya. (Purnama, 2016) penelitian R \& D adalah penelitian yang memiliki tujuan untuk membuat produk berdasarkan kajian kebutuhan, mengembangkan produk, penilaian produk, perbaikan dan menyebarkan produk. (Samsu, 2017) (R \& D) merupakan sebuah langkah yang dipakai dalam perkembangan dan validasi produk pada bidang pendidikan. Perkembangan teknologi sangat mempengaruhi segala aspek bidang, seperti bidang pendidikan. Dalam bidang pendidikan perkembangan media pembelajaran sangat berkembang pesat dalam proses pembelajaran seperti media pembelajaran modul. Modul sekarang sudah dikembangkan menjadi E-Modul. Menurut (Elvarita et al., 2020) e-Modul merupakan suatu aplikasi dalam proses belajar yang memiliki metode, materi dan penilaian yang dibuat secara sistematik dan membawa siswa untuk sampai pada tujuan kompetensi yang seharusnya dengan tingkat kerumitannya. Sedangkan (Solikin, 2018) menyatakan e-Modul adalah sebuah bentuk tulisan yang berformat elektronik dan bermanfaat untuk pembelajaran dan pendapat (Laili, 2019) E-Modul adalah sebuah media belajar mandiri yang berisi materi pembelajarana.

\section{Metode}

Penelitian ini menggunakan jenis penelitian pengembangan atau Research and Developent (R \& D). Penelitian dan pengembangan menurut (Sugiyono, 2013) merupakan sebuah metode yang dipakai dalam penelitian untuk membuat produk serta membuktikan kegunaan dari produk itu sendiri. (Kamal, 2020) menyatakan bahwa penelitian ini memiliki tujuan untuk membuat desain, produk tertentu yang melewati proses rancangan, percobaan dan perbaikan dalam capain kualitas dan standar tertentu. Penelitian ini berkembang dari penelitian dan pengembangan bermacam bentuk seperti software ataupun hardware yang berupa modul, buku atau media belajar lainnya. Dalam penelitian ini produk yang akan digunakan atau dikembangkan yaitu e-Modul pembelajaran.

Dari penelitian sebelumnya penggunaan model ADDIE banyak digunakan pada e-Modul. Untuk itu peneliti ingin menggunakan model penelitian ADDIE yang dikembangkan oleh Dick and Carry pada tahun 1996. Model ADDIE ini merupakan singkatan dari Analysis, Design, Development, Implementation, and Evaluation. (Rohaeni, 2020) menjelaskan bahwa Model ADDIE merupakan suatu tahapan yang dipakai dalam pengembangan pada produk pendidikan dan bisa di petanggung jawabkan dengan penelitian pengembangan. Pada singkatan model ADDIE merupakan sebuah rangkaian atau tahapan yang terstruktur dan sistematis 
dalam menggunakannya. Model ADDIE dapat diterapkan pada media pembelajaran seperti buku, e-Modul atau bahan ajar lainnya.

\section{Hasil dan Pembahasan}

Setelah peneliti tinjau secara mendalam mengenai pendapat para ahli tentang modul, peneliti menyimpulkan bahwa modul merupakan bahan ajar mandiri yang disusun secara digital yang tujuannya agar mahasiswa dapat belajar dengan bimbingan dosen maupun belajar secara mandiri dengan efisien. Modul merupakan media pembelajaran yang dirancang untuk dapat dipelajari oleh mahasiswa secara mandiri disesuaikan dengan tingkat kemampuannya (Direktorat Tenaga Kependidikan, 2008). Modul berjudul Analisis Kurikulum Pendidikan Dasar memuat materi dan di perkuat dengan unsur penguat pembelajaran seperti latihan, dan video penjelasan langsung dari dosen pengampu. Modul ini sebagai produk dari penelitian pengembangan dikembangkan melalui model ADDIE dengan beberapa tahap yang meliputi tahap analysis (analisis), design (perancangan), development (pengembangan), implementation (implementasi), dan evaluation (evaluasi). Pada tahap analysis (analisis) dilakukan analisis learning outcome, analisis materi, dan analisis karakter mahasiswa. Dari tahap ini didapatkan bahwa perlu dikembangkan modul pembelajaran yang memuat kegiatan yang relevansi dengan materi. Relevansi artinya membuat kegiatan pembelajaran sesuai dengan perkembangan kurikulum pendidikan dasar yang berlaku saat ini.

Pada tahap design (perancangan) dilakukan perancangan modul pembelajaran meliputi langkah pertama merumuskan judul, tujuan, pemilihan bahan, penyusunan kerangka, dan pengumpulan bahan. Langkah kedua, menyusun draf awal e-modul berformat Microsoft Power Point dan PDF. Langkah ketiga, mengkonversi file modul dari format PDF menjadi berformat flipbook. Langkah keempat, membuat strategi pengujian. Dan langkah terakhir, menyusun instrumen penilaian modul pembelajaran. Instrumen penilaian modul pembelajaran terdiri dari instrument penilaian validitas dan praktikalitas. Instrumen penilaian keefektifan diambil dari hasil tes kognitif mahasiswa menggunakan pre-test dan post-test dengan rumus gain score. Sebelum digunakan, instrumen tersebut divalidasi oleh terlebih dahulu oleh dosen ahli materi dan media agar diperoleh instrumen yang tepat dalam menilai modul pembelajaran. Setelah divalidasi, didapatkan instrumen penilaian produk yang valid.

Tahap development (pengembangan) dilakukan pengembangan rancangan modul pembelajaran, penyuntingan modul pembelajaran, validasi, dan revisi modul pembelajaran. Pengembangan modul pembelajaran memuat kegiatan yang telah disesuaikan dengan pendekatan pembelajaran berbasis aplikasi offline (flipbook). Setelah selesai disusun, modul pembelajaran dikonsultasikan kepada dosen pembimbing untuk mendapatkan masukan tentang kekurangan-kekurangan yang ada dalam modul pembelajaran tersebut. Setelah mengkonsultasikn modul pembelajaran kepada dosen pembimbing, dilakukan penyuntingan terhadap modul pembelajaran. Setelah penyusunan modul pembelajaran selesai tahap selanjutnya adalah validasi atau penilaian modul dan instrumen tes hasil belajar mahasiswa oleh validator. Validasi dilakukan oleh 4 orang ahli media dan 3 orang ahli materi, sehingga total dari validator adalah 7 orang. Pada langkah ini akan diperoleh nilai dan kategori modul pembelajaran dari hasil penilaian modul pembelajaran oleh ahli materi dan ahli media. Tujuan dari validasi adalah untuk memperoleh penilaian, masukan, dan saran untuk perbaikan dan penyempurnaan modul pembelajaran sehingga akan diperoleh produk modul pembelajaran yang terhindar dari kesalahan agar layak diuji cobakan. Tahap selanjutnya dilakukan revisi atau perbaikan seperlunya terhadap modul pembelajaran sesuai masukan, dan saran para ahli.

Tahap implementasi (implementasi) yaitu pada saat modul pembelajaran dinyatakan layak oleh ahli materi dan ahli media, peneliti melakukan implementasi dalam pembelajaran yaitu melaksanakan perangkat dan menguji cobakan secara terbatas modul kepada 24 mahasiswa yang mengambil mata kuliah Analisis Kurikulum Pendidikan Dasar di jurusan Kurikulum Teknologi Pendidikan angkatan 2019. Hasil dari uji coba terbatas terdapat 25 butir soal pilihan ganda yang valid. Pada tahap implementasi ini akan diperoleh data keefektivan modul. Data keefektifan modul pembelajaran diperoleh dari tes hasil belajar. Kegiatan pembelajaran di kelas pada setiap pertemuan hampir sama pelaksanaannya. Pada saat pembelajaran, mahasiswa bekerja secara mandiri maupun berdiskusi secara kelompok. Pada umumnya pembelajaran berlangsung lancar, namun ada beberapa kendala yaitu mahasiswa masih terlalu lama dalam melakukan kegiatan diskusi karena mereka tidak terbiasa melakukan diskusi dan mengemukan pendapat. Setelah pembelajaran kedua dan selanjutnya, mahasiswa sudah aktif mengemukakan pendapatnya dalam proses pembelajaran yang dilakukan. Selain itu, mahasiswa juga berusaha berpikir kritis dalam menyelesaikan permasalahan yang disajikan. Namun sesekali mahasiswa menanyakan hal yang tidak mereka pahami kepada dosen. 
Tahap terakhir adalah tahap evaluation (evaluasi). Evaluasi yang dilakukan adalah dengan menganalisis data hasil penilaian modul pembelajaran oleh dosen ahli. Selama proses uji coba berlangsung saran dan masukan dari dosen dan mahasiswa ditampung untuk digunakan sebagai perbaikan atau revisi terhadap modul pembelajaran yang dikembangkan oleh peneliti. Berdasarkan hasil penelitian, modul pembelajaran yang dihasilkan berkualitas memenuhi kelayakan ditinjau dari aspek validitas, praktikalitas, dan efektivitas. Aspek penilaian modul pembelajaran dikatakan layak berdasarkan aspek validitas oleh validator ahli media dan ahli materi dengan kriteria valid.

Berdasarkan hasil validasi ahli pada uji validasi produk oleh validator media dan validator materi. Kevalidan bahan ajar e-modul dapat dilihat dari hasil persentase rata-rata skor validator ahli materi adalah $92,98 \%$, dengan rincian aspek materi $92,42 \%$ dan aspek pembelajaran $93,75 \%$. Untuk persentase rata-rata skor validator ahli media adalah $78,57 \%$, dengan rincian aspek tampilan $77,8 \%$, aspek pemanfaatan $80 \%$, dan aspek kemudahan $79,16 \%$. Penilaian modul pembelajaran menggunakan angket respon dosen mendapat skor persentase rata-rata $98,95 \%$ dengan kriteria sangat praktis. Penilaian modul pembelajaran dengan rincian aspek kualitas produk $96,85 \%$, aspek penyajian materi $100 \%$, dan aspek manfaat $100 \%$. Penilaian modul pembelajaran menggunakan angket respon mahasiswa mendapatkan skor persentase rata-rata $87,76 \%$ dengan kriteria sangat praktis. Dengan rincian penilaian, aspek kualitas produk $87,75 \%$, aspek penyajian materi $87,21 \%$, dan aspek manfaat $88,33 \%$. Secara keseluruhan, dosen dan mahasiswa merasa terbantu dengan adanya modul pembelajaran dikarenakan modul pembelajaran tersebut memudahkan proses pembelajaran baik dalam penyampaian materi maupun dalam pemahaman materi. Hasil penelitian menunjukan bahwa hasil verifikasi validator materi memberikan skor persentase 93\% kategori sangat valid, pakar desain pembelajaran dengan persentase $82 \%$ kategori valid, pakar media dengan persentase $86 \%$ kategori valid dan $86 \%$ untuk keefektifitas pemakaian pada media pembelajaran (Ricu Sidiq et al, 2020).

\section{Simpulan}

Berdasarkan hasil penelitian pengembangan perangkat pembelajaran berbasis android seiring dengan pandemi Covid-19, diperoleh kesimpulan sebagai berikut : Pengembangan yang dilakukan pada penelitian ini menghasilkan e-modul berbasis android menggunakan flip pdf profesional pada mata kuliah Analisis Kurikulum Pendidikan Dasar yang dikembangkan menurut model ADDIE yang terdiri dari Analysis, Design, Development, Implementation, dan Evaluation. Modul pembelajaran berbasis android yang dikembangkan oleh peneliti sudah sesuai dengan kriteria valid oleh tim validator ahli media dan ahli materi. Hal ini dibuktikan pada modul dan instrumen penilaian hasil belajar yang dikembangkan setelah menyelesaikan tahap penilaian oleh para dosen ahli media dan dosen ahli materi memiliki nilai sebesar yaitu 92,98\% nilai kevalidan aspek materi, dan $75,57 \%$ nilai kevalidan aspek media. Penilaian dari aspek kepraktisan, modul pembelajaran berbasis android yang dikembangkan sudah sesuai dengan kriteria kepraktisan yaitu sangat praktis. Analisis kepraktisan dilakukan berdasarkan hasil angket respon dosen pengampu dan mahasiswa setelah menggunakan modul pembelajaran, serta hasil observasi keterlaksanaan pembelajaran. Dari hasil angket praktikalitas oleh dosen pengampu, diperoleh nilai rata-rata $98,95 \%$ dengan rincian aspek kualitas produk $96,85 \%$, aspek penyajian materi $100 \%$, dan aspek manfaat $100 \%$. Untuk hasil angket praktikalitas oleh mahasiswa, diperoleh nilai rata-rata $87,76 \%$ dengan rincian aspek kualitas produk $87,75 \%$, aspek penyajian materi $87,21 \%$, dan aspek manfaat $88,33 \%$. Pada tahap analisis efektivitas, modul pembelajaran yang dikembangkan peneliti sudah sesuai dengan kriteria efektif. Analisis menggunakan rumus gain score. Hasil analisis uji efektivitas berdasarkan tes kognitif mahasiswa melalui hasil belajar yang dilihat dari hasil pre-test dan post-test rumus gain score didapatkan nilai rata-rata 74,29\% dengan kategori tinggi. Hal ini menunjukkan mahasiswa yang sebelumnya mempunyai pengetahuan dasar yang memiliki nilai pretest rendah tetapi setelah belajar menggunakan e-modul dan sudah dapat memahami materi sehingga nilai posttest lebih tinggi dari nilai pretest.

\section{Referensi}

Arifin, M. Z., Ulfa, S., \& Praherdhiono, H. (2018). Pengembangan kurikulum muatan lokal karawitan sebagai upaya mengkonstruksi pengetahuan dan pelestarian budaya jawa di jenjang sma. Jurnal Kajian Teknologi Pendidikan, 1, 2-10. http://journal2.um.ac.id/index.php/jktp/article/view/3707

Diofanu, A., Wijoyo, S. H., \& Wicaksono, S. A. (2020). Pengembangan E-Modul Berbasis Electronic Publication (EPUB) Menggunakan Model Pengembangan ADDIE Pada Mata Pelajaran Pemrograman Dasar di SMK Negeri 4 Malang. Jurnal Pengembangan Teknologi Informasi Dan Ilmu Komputer, 4(7), 2204-2211.

Dwi Lestari, H., \& Putu Parmiti, D. P. P. (2020). Pengembangan E-Modul Ipa Bermuatan Tes Online Untuk Meningkatkan Hasil Belajar. Journal of Education Technology, 4(1), 73. 
https://doi.org/10.23887/jet.v4i1.24095

Ellysia, A., Irfan, D., Pendidikan, P., Elektronika, T., Teknik, F., Negeri, U., Teknik, J., Fakultas, E., \& Padang, U. N. (2021). Pengembangan e - Modul Dengan Flip PDF Professional pada Mata Pelajaran Dasar Listrik dan Elektronika P - ISSN : 2302-3295. 9(3).

Elvarita, A., Iriani, T., \& Handoyo, S. S. (2020). Peningkatan Materi Pelajaran Mekanika Tanah. JPenSil, 09(01), 17. http://journal.unj.ac.id/unj/index.php/jpensil

Febrianti, F. (2021). Pengembangan Digital Book Berbasis Flip PDF Professional untuk Meningkatkan Kemampuan $\begin{array}{lllll}\text { Literasi Sains } & \text { Siswa. } & \text { Jurnal.Ugj.Ac.Id, } & 4(2), & 102-115 .\end{array}$ http://jurnal.ugj.ac.id/index.php/Caruban/article/view/5354

Gufran, G., \& Mataya, I. (2020). Pemanfaatan E-Modul Berbasis Smartphone Sebagai Media Literasi Masyakarat. JISIP (Jurnal Ilmu Sosial Dan Pendidikan), 4(2). https://doi.org/10.36312/jisip.v4i2.1060

Habiburrahman, \& Sulistyowati, R. (2020). Pengembangan e-modul berbasis web sebagai media pembelajaran pada materi mengidentifikasi pelanggan mata pelajaran komunikasi bisnis kelas X BDP di smk negeri 1 Surabaya. Jurnal Pendidikan Tata Niaga (JPTN), 8(2), 875-881. https://www.jurnalmahasiswa.unesa.ac.id/

Hakiki, M., Fadli, R., Putra, Y. I., \& Pertiwi, I. P. (2021). Pengembangan E-Modul Berorientasi Higher Order Thinking Skills (Hots) Pada Pelajaran Ilmu Pengetahuan Alam (Ipa) Kelas Vi Sekolah Dasar. Jurnal Muara Pendidikan, 6(1), 50-57. https://doi.org/10.52060/mp.v6i1.513

Herawati, N. S., \& Muhtadi, A. (2018). Pengembangan modul elektronik (e-modul) interaktif pada mata pelajaran Kimia kelas XI SMA. Jurnal Inovasi Teknologi Pendidikan, 5(2), 180-191. https://doi.org/10.21831/jitp.v5i2.15424

Hermawan, Y. C., Juliani, W. I., \& Widodo, H. (2020). Konsep Kurikulum Dan Kurikulum Pendidikan Islam. Jurnal MUDARRISUNA: Media Kajian Pendidikan Agama Islam, 10(1), 34. https://doi.org/10.22373/jm.v10i1.4720

Irhamna, I., Rosdianto, H., \& Murdani, E. (2017). Penerapan Model Learning Cycle 5E untuk Meningkatkan Keterampilan Berpikir Kritis Siswa Pada Materi Fluida Statis Kelas VIII. Jurnal Fisika FLUX, 14(1), 61. https://doi.org/10.20527/flux.v14i1.3839

Kamal, M. (2020). Research and Development ( R \& D ) Tadribat / Drill Madrasah Aliyah Class X Teaching Materials Arabic Language. Junal Sejarah, Pendidikan Dan Humaniora, 4(1), 10-18. https://doi.org/10.36526/js.v3i2.e-ISSN

Khairinal, K., Suratno, S., \& Aftiani, R. Y. (2021). Pengembangan Media Pembelajaran E-Book Berbasis Flip Pdf Professional Untuk Meningkatkan Kemandirian Belajar Dan Minat Belajar Siswa Pada Mata Pelajaran Ekonomi Siswa Kelas X Iis 1 Sma Negeri 2 Kota Sungai Penuh. Jurnal Manajemen Pendidikan Dan Ilmu Sosial, 2(1), 458-470.

Laili, I. (2019). Efektivitas Pengembangan E-Modul Project Based Learning Pada Mata Pelajaran Instalasi. Jurnal Imiah Pendidikan Dan Pembelajaran, $\quad 3, \quad 306-315$. https://ejournal.undiksha.ac.id/index.php/JIPP/article/download/21840/13513

Maharani, M., Wati, M., \& Hartini, S. (2017). Pengembangan Alat Peraga Pada Materi Usaha dan Energi Untuk Melatihkan Keterampilan Proses Sains Melalui Model Iquiry Discovery Learning (IDL terbimbing). Berkala Ilmiah Pendidikan Fisika, 5(3), 351. https://doi.org/10.20527/bipf.v5i3.4043

Muhammad Irsyad. (2020). Thawalib | Jurnal Kependidikan Islam. 1(2), 103-130.

Nisa, H. A., Mujib, \& Putra, R. W. Y. (2020). Efektivitas E-modul dengan Flip PDF Professional Berbasis Gamifikasi terhadap Siswa SMP. Jurnal Pendidikan Matematika Raflesia, 5(2), $13-25$. https://ejournal.unib.ac.id/index.php/jpmr/article/view/11406/5732

Nurhidayati, A., Putro, S. C., \& Widiyaningtyas, T. (2018). Penerapan Model Pbl Berbantuan E-Modul Berbasis Flipbook Dibandingkan Berbantuan Bahan Ajar Cetak Pengaruhnya Terhadap Hasil Belajar Pemrograman Siswa Smk. Teknologi Dan Kejuruan: Jurnal Teknologi, Kejuruan, Dan Pengajarannya, 41(2), 130-138. https://doi.org/10.17977/um031v41i22018p130

Purnama, S. (2016). Metode Penelitian Dan Pengembangan (Pengenalan Untuk Mengembangkan Produk Pembelajaran Bahasa Arab). LITERASI (Jurnal Ilmu Pendidikan), 4(1), 19. https://doi.org/10.21927/literasi.2013.4(1).19-32

Putra, A., Syarifuddin, H., \& Zulfah, Z. (2018). Validitas Lembar Kerja Peserta Didik Berbasis Penemuan Terbimbing dalam Upaya Meningkatkan Pemahaman Konsep dan Kemampuan Penalaran Matematis. Edumatika : Jurnal Riset Pendidikan Matematika, 1(2), 56. https://doi.org/10.32939/ejrpm.v1i2.302

Putra, K. W. B., Wirawan, I. M. A., \& Pradnyana, G. A. (2017). Pengembangan E-Modul Berbasis Model Pembelajaran Discovery Learning Pada Mata Pelajaran "Sistem Komputer" Untuk Siswa Kelas X Multimedia Smk Negeri 3 Singaraja. Jurnal Pendidikan Teknologi Dan Kejuruan, 14(1), 40-49. https://doi.org/10.23887/jptk.v14i1.9880

Rachmi, A. (2020). Pengembangan E-Modul Berbasis Android Mata Kuliah Struktur Beton II. Jurnal PenSil, 9(3), 152-158. https://doi.org/10.21009/jpensil.v9i3.10815

Ramadayanty, M., Sutarno, S., \& Risdianto, E. (2021). Pengembangan E-Modul Fisika Berbasis Multiple 
Reprsentation Untuk Melatihkan Keterampilan Pemecahan Masalah Siswa. Jurnal Kumparan Fisika, 4(1), 17-24. https://doi.org/10.33369/jkf.4.1.17-24

Ricu Sidiq, \& Najuah. (2020). Pengembangan E-Modul Interaktif Berbasis Android pada Mata Kuliah Strategi Belajar Mengajar. Jurnal Pendidikan Sejarah, 9(1), 1-14. https://doi.org/10.21009/jps.091.01

Rindaryati, N. (2021). E-Modul Counter Berbasis Flip Pdf pada Mata Pelajaran Penerapan Rangkaian Elektronika. Jurnal Imiah Pendidikan Dan Pembelajaran, 5(2), 192. https://doi.org/10.23887/jipp.v5i2.31240

Rohaeni, S. (2020). Pengembangan Sistem Pembelajaran Dalam Implementasi Kurikulum 2013 Menggunakan Model Addie Pada Anak Usia Dini. Instruksional, 1(2), 122. https://doi.org/10.24853/instruksional.1.2.122130

Samsu. (2017). Metode penelitian: teori dan aplikasi penelitian kualitatif, kuantitatif, mixed methods, serta research \& development. In Diterbitkan oleh: Pusat Studi Agama dan Kemasyarakatan (PUSAKA).

Seruni, R., Munawaoh, S., Kurniadewi, F., \& Nurjayadi, M. (2019). Pengembangan Modul Elektronik (E-Module) Biokimia Pada Materi Metabolisme Lipid Menggunakan Flip Pdf Professional. JTK (Jurnal Tadris Kimiya), 4(1), 48-56. https://doi.org/10.15575/jtk.v4i1.4672

Simamora, A. H., Sudarma, I. K., \& Prabawa, D. G. A. P. (2019). Pengembangan E-Modul Berbasis Proyek Untuk Mata Kuliah Fotografi Di Jurusan Teknologi Pendidikan Fakultas Ilmu Pendidikan Undiksha. Journal of Education Technology, 2(1), 51. https://doi.org/10.23887/jet.v2i1.13809

Solikin, I. (2018). Implementasi E-Modul pada Program Studi Manajemen Informatika Universitas Bina Darma Berbasis Web Mobile. Jurnal RESTI (Rekayasa Sistem Dan Teknologi Informasi), 2(2), $492-497$. https://doi.org/10.29207/resti.v2i2.393

Sriwahyuni, I., Risdianto, E., \& Johan, H. (2019). Pengembangan Bahan Ajar Elektronik Menggunakan Flip Pdf Professional Pada Materi Alat-Alat Optik Di Sma. Jurnal Kumparan Fisika, 2(3), $145-152$. https://doi.org/10.33369/jkf.2.3.145-152

Sugihartini, N., \& Jayanta, N. L. (2017). Pengembangan E-Modul Mata Kuliah Strategi Pembelajaran. Jurnal Pendidikan Teknologi Dan Kejuruan, 14(2), 221-230. https://doi.org/10.23887/jptk-undiksha.v14i2.11830

Sugiyono. (2013). Metode Penelitian Kuantitatif, Kualitatif, dan Tindakan.

Suharsimi, A. (2009). Dasar-dasar evaluasi pendidikan. Jakarta: Bumi Aksara

Sukendro, S. J., Wiyatini, T., Ginanjar, R., \& Yodong. (2019). Prototipe Aplikasi Analisis Butir Soal Ujian Akhir Semester Genap Mata Kuliah Konsep Dasar Pelayanan Asuhan Kesehatan Gigi Dan Mulut Tahun Akademik 2018/2019 Berdasarkan Validitas, Reliabilitas, Daya Pembeda, Tingkat Kesukaran, dan Efektivitas Pengecoh. Jurnal Kesehatan Gigi, 5(2), 65-84.

Ummah, R., Suarsini, E., \& Lestari, S. R. (2020). Pengembangan E-modul Berbasis Penelitian Uji Antimikroba pada Matakuliah Mikrobiologi. Jurnal Pendidikan: Teori, Penelitian, Dan Pengembangan, 5(1), 572-579.

Wulansari, E. W., Kantun, S., \& Suharso, P. (2018). Pengembangan E-Modul Pembelajaran Ekonomi Materi Pasar Modal Untuk Siswa Kelas Xi Ips Man 1 Jember Tahun Ajaran 2016/2017. JURNAL PENDIDIKAN EKONOMI: Jurnal Ilmiah Ilmu Pendidikan, Ilmu Ekonomi Dan Ilmu Sosial, 12(1), 1. https://doi.org/10.19184/jpe.v12i1.6463 